\title{
REGRESSIVE MYOCARDIAL INFARCTION WITH ST ELEVATION (STEMI) TREATED WITH CONSERVATIVE MEDICINAL THERAPY
}

\author{
Alexis Al Karaky, \\ Snezhanka T. Tisheva- \\ Gospodinova $^{1}$ \\ Department of Cardiology, \\ Nevers Hospital Center, \\ France \\ ${ }^{1}$ Cardiology Division, \\ Medical University - Pleven, \\ Bulgaria
}

\author{
Corresponding Author: \\ Alexis Al Karaky \\ Department of Cardiology, \\ Nevers Hospital Center \\ 1 Patrick Guillot Str. \\ Nevers, 58000 \\ France \\ e-mail: alexiscardiologie@gmail.com
}

Received: February 18, 2019

Revision received: June 10, 2019

Accepted: July 30, 2019

\section{Summary}

The case presented is that of a young man with atypical pathogenesis of myocardial infarction with ST-elevation (STEMI) after physical stress. It was provoked by partial thrombosis of the distal segment of the left main coronary artery (LM) at the bifurcation of the left anterior descending artery. After the emergency treatment, the disease process underwent reverse development without any consequences for left ventricular kinetics.

Key words: Acute myocardial infarction, STEMI, chest pain, coronary thrombosis, optical coherence tomography (OCT)

\section{Introduction}

We present a case of an acute coronary syndrome with ST elevation that was treated after conservative therapeutic scheme after clinical assessment of the patient. The coronary network status was also assessed using advanced technical methods. A team of cardiologists discussed the case. This led to proper decision-making for the patient's medical care.

Notwithstanding the tendencies for such cases to be managed by coronary interventional treatments, this case illustrates the importance of collaborative decision-making for individualized and personalized treatment strategies that rely on practice guidelines and recommendations.

\section{The case description}

We report a 31-years-old male patient. In the beginning, he was admitted to the hospital complaining of persistent constrictive chest pain with duration of 90 minutes. The pain appeared one hour after he had played football. He did not mention any past illnesses. The patient had no personal previous medical history. There was a risk factor- a family history of cardiovascular disease. At the age of 50, his father had myocardial infarction. On the maternal side, there were an aunt and an uncle who had suffered from ischemic coronary disease before age 60 .

On hospital admission, the electrocardiogram 
showed ST-elevation of the lower and lateral leads, and ST-depression of the anterior leads (Figure 1).



Figure 1. First ECG: ST-elevation of the lower and lateral leads and ST-depression of the anterior leads

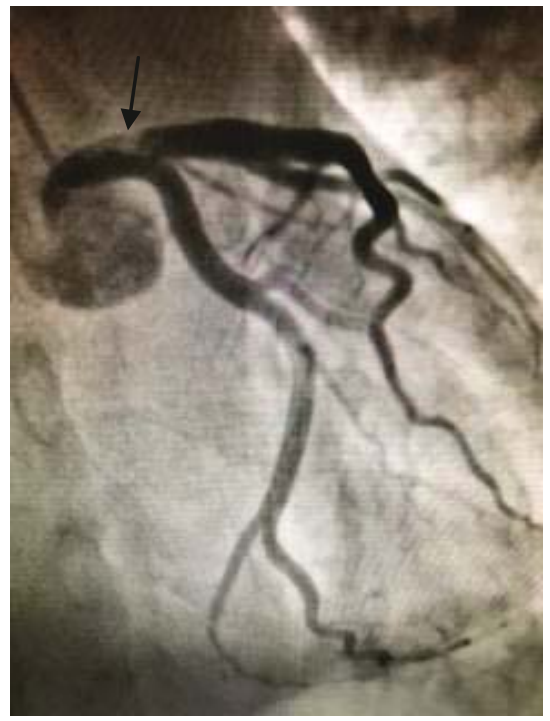

Figure 2. Coronarography: non-obstructive left main coronary artery distal segmental thrombosis, bifurcation with the left anterior interventricular artery

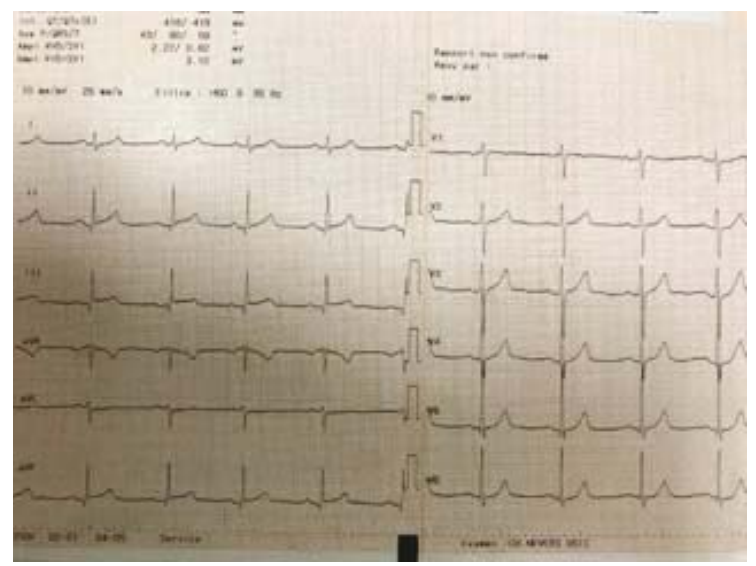

Figure 3. Second ECG: quasi-total regression of ST elevation
The patient demonstrated an increase in myocardial necrosis markers (troponin Ic).

A coronarography test was done 2 hours after the symptom onset and after administration of $250 \mathrm{mg}$ of acetylsalicylic acid IV, heparin 5000 IU IV and $60 \mathrm{mg}$ of prasugrel PO. It showed non-obstructive left main coronary artery (LM) distal segmental thrombosis, at the bifurcation of the left anterior descending artery (Figure 2).

At this point, the chest pain and the abovedescribed electrocardiographic abnormalities disappeared (Figure 3). Therefore, the decision was to continue the dual anti-aggregate therapy, anticoagulation therapy with subcutaneous fondaparinux (arixtra) and intravenous Anti-GP II / III A (tirofiban) for 24 hours.

A second coronarography was done on the 3rd day. It showed a persistent minimal heterogeneous aspect of the distal part of the left main coronary artery and the ostium of the left anterior descending artery (LAD) and, therefore, an essential regression of thrombosis (Figure 4).

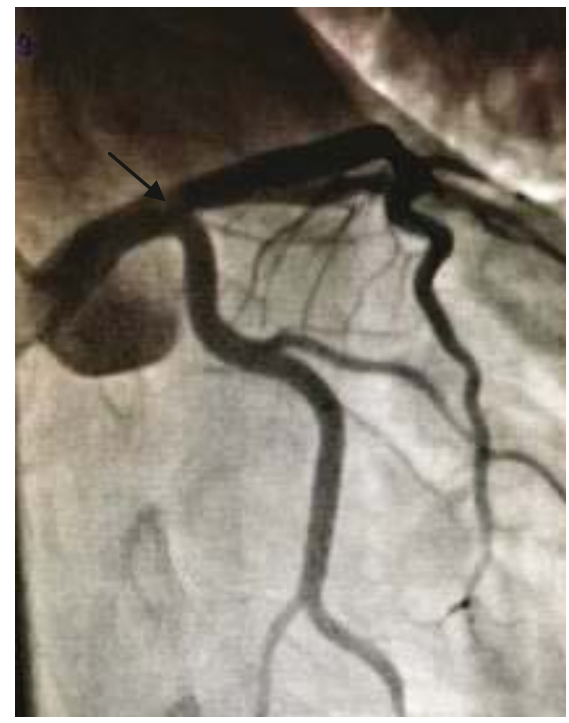

Figure 4. Coronarography on day 3: partial regression of the left main coronary artery distal segmental thrombosis, bifurcation with the left anterior interventricular artery

Optical coherence tomography (OCT) confirmed a plaque rupture without significant stenosis (Figure 5).

Echocardiography showed preserved systolic function of the left ventricle (LVEF $=60 \%$ ) and homogeneous left ventricular kinetics. No valvulopathy was detected, and the size and capacity of the right ventricular cavity were normal. 


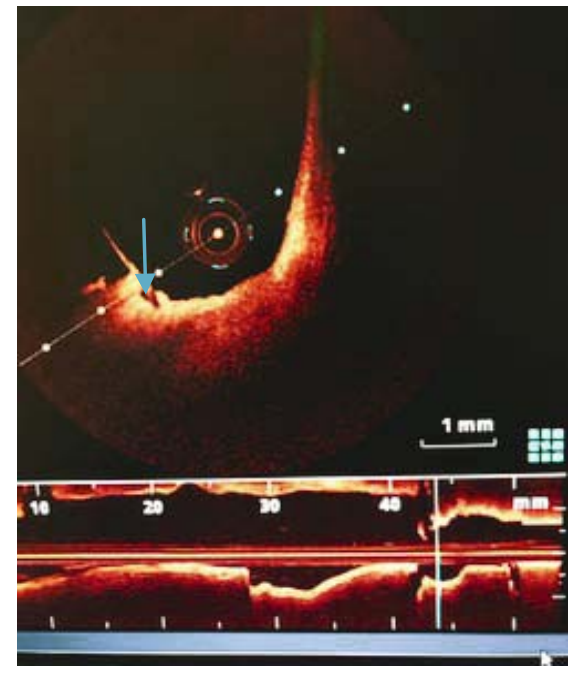

Figure 5. Optical coherence tomography confirmed a plaque rupture without significant stenosis

The myocardial necrosis markers were as follows: troponin Ic $-0.25 \mathrm{mcg} / \mathrm{l}$ on admission, and the peak value of troponin on the hour 7 was $15.07 \mathrm{mcg} / 1$

The patient was discharged from hospital with regular therapy for 12 months with prasugrel 10 mg PO QD, acetylsalicylic acid 75 mg PO QD, atorvastatin $40 \mathrm{mg}$ PO QD, bisoprolol $2.5 \mathrm{mg}$ PO QD, pantoprazole $40 \mathrm{mg}$ PO QD and finally - one month of fondaparinux (arixtra) $7.5 \mathrm{mg} \mathrm{SC}$ QD.

Control coronary angiography done after two months showed a small atheromatous plaque of the left main coronary artery in the distal segment without significant stenosis with neither thrombosis nor plaque rupture (Figure 6).

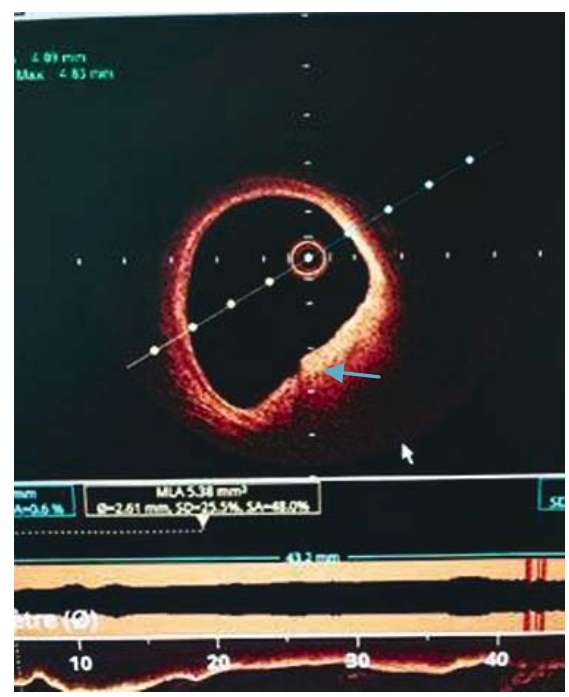

Figure 6. Control coronary angiography after two months: a small atheromatous plaque of the left stem coronary artery in the distal segment without significant stenosis
The thrombophilia profile test result was normal. The homocysteine, anti-thrombin III, protein $\mathrm{C}$ and Protein $\mathrm{S}$ values were normal, as were the coagulation factors II, V, VII, X. The activated protein $\mathrm{C}$ resistance test was normal. No anti-cardiolipin antibodies, anti- $\beta 2$ glycoprotein 1 antibodies and lupus anticoagulant were detected.

\section{Discussion}

The case reported refers to a regressive myocardial infarction with ST-elevation (STEMI) without signs of aggravation, treated in 2015. The thrombus did not obstruct the left main coronary artery at the bifurcation of the left interventricular artery and resulted from a postexercise plaque rupture [1].

We chose a medical conservative therapeutic strategy taking into consideration that the ST elevation regressed spontaneously and the chest pain subsided (signs of reperfusion). The coronary flow was TIMI III. Therefore, neither for fibrinolysis therapy nor surgical revascularization could be appropriate [2]. More often, the primary angioplasty in this severe thrombotic environment may increase the risk of coronary flow alteration [3].

Many studies and publications support the strategy of deferred angioplasty [4-6] which avoids coronary stenting in certain patients and allows selection of conservative medical treatment with anti-thrombotic glycoprotein IIb/IIIa inhibitors, double antiaggregant and anticoagulant [7, 8]. In fact, N. Amabile et al. (2015) showed the feasibility and the safety of thrombus analysis in STEMI acute phase and its regression later on using OCT [8]. All prescribed medications for the initial medical treatment in the STEMI acute phase and in the discharge prescription meet the recommendations of the ESC [9] except for prasugrel, which should be substituted by ticagrelor.

\section{Conclusions}

Partial thrombosis of the left main coronary artery at the bifurcation of the left interventricular artery, due to a small plaque rupture resulting in a temporary ST-elevation regresses after urgent medical treatment. There are no consequences 
in left ventricular kinetics. An OCT test has confirmed the disappearance of thrombosis after two months.

\section{Acknowledgements}

This publication is not a part of a scientific project.

\section{References}

1. Sghaier A, Milouchi S, Ghannem L, Ghannem L, Ghannem M. Exercise-induced coronary thrombosis. Annales de Cardiologie et d'Angéiologie. Ann Cardiol Angeiol (Paris). 2017;66(6):421-4.

2. Kolh P, Windecker S, Alfonso F, Collet JP, Cremer J, Falk V, et al. 2014 ESC/EACTS Guidelines on myocardial revascularization: the task force on myocardial revascularization of the European Society of Cardiology (ESC) and the European Association for CardioThoracic Surgery (EACTS). Developed with the special contribution of the European Association of Percutaneous Cardiovascular Interventions (EAPCI). Eur J Cardiothorac Surg. 2014;46(4):517-92.

3. Goto K, Lansky AJ, Nikolsky E, Fahy M, Feit F, Ohman, et al. Prognostic significance of coronary thrombus in patients undergoing percutaneous coronary intervention for acute coronary syndromes: a subanalysis of the ACUITY (Acute Catheterization and Urgent Intervention Triage strategY) trial. JACC Cardiovasc Interv. 2011;4(7):769-77.

4. Meneveau N, Séronde MF, Descotes-Genon V, Dutheil J, Chopard R, Ecarnot F, et al. Immediate versus delayed angioplasty in infarct-related arteries with TIMI III flow and ST-segment recovery: a matched comparison in acute myocardial infarction patients. Clin Res Cardio.1 2009;98(4):257-64.
5. Freixa X, Belle L, Joseph L, Tanguay JF, Souteyrand GL,'Allier PL, et al. Immediate vs. delayed stenting in acute myocardial infarction: a systematic review and meta-analysis. EuroIntervention 2013;8(10):1207-16.

6. Carrick D, Oldroyd KG, McEntegart M, Haig C, Petrie MC, Eteiba H, et al. A randomized trial of deferred stenting versus immediate stenting to prevent no- or slow-reflow in acute ST-segment elevation myocardial infarction (DEFERSTEMI). J Am Coll Cardiol. 2014;63(20):208898.

7. Kelbaek H, Engstrøm T, Ahtarovski KA, Lønborg J, Vejlstrup N, Pedersen F, et al. Deferred stent implantation in patients with STsegment elevation myocardial infarction: a pilot study. EuroIntervention 2013;8(10):1126-33

8. Amabile N, Hammas S, Fradi S, Souteyrand G, Veugeois A, Belle L, Motreff P, et al. Intracoronary thrombus evolution during acute coronary syndrome: regression assessment by serial optical coherence tomography analyses. Eur Heart J Cardiovasc Imaging. 2015;16(4):433-40.

9. Ibanez B, James S, Agewall S, Antunes MJ, Bucciarelli-Ducci C, Bueno H, et al. 2017 ESC Guidelines for the management of acute myocardial infarction in patients presenting with ST-segment elevation: The Task Force for the management of acute myocardial infarction in patients presenting with ST-segment elevation of the European Society of Cardiology (ESC).. Eur Heart J 2018;39(2):119-77. 